\title{
Life-trait evolution of a parasite strongyle nematode in response to host resistance: an experimental approach using Haemonchus contortus in black belly lambs
}

\author{
Maité Saulai ${ }^{\mathrm{a}, \mathrm{b}}$, Jacques CABARET ${ }^{\mathrm{b}}$, Gérard Hostache ${ }^{\mathrm{a}}$, \\ Nathalie MANDONNET ${ }^{\mathrm{a}}$, Gilles AUMONT ${ }^{\mathrm{a}, \mathrm{b}, *}$ \\ ${ }^{a}$ Unité de recherches zootechniques, Institut national de la recherche agronomique, \\ 97170 Petit Bourg, Guadeloupe, France \\ ${ }^{\text {b }}$ Station de pathologie aviaire et de parasitologie, Institut national de la recherche \\ agronomique, 37380 Nouzilly, France
}

\begin{abstract}
The selection of resistant sheep in farms could increase the selective pressure during the parasitic phase and this might affect life-traits of the parasite nematodes. Before selecting for host resistance, it is crucial to estimate the potential adaptation of these nematodes to resistant hosts. The objective of this study was to determine the ability of the nematode parasite, Haemonchus contortus, to adapt its life-traits to different resistance states of sheep. The isolates of the nematode Haemonchus contortus were obtained from five locations in Guadeloupe (French West Indies) and a synthetic strain was prepared, which was representative of these isolates on the basis of isoenzymes and morphometric traits. This synthetic strain was reproduced during 10 generations in hosts of marked different resistance status. Primary infected 6-to 8-months old Black Belly ewe lambs, a wellknown to be highly resistant breed to nematode parasites, were used as resistant host. The "susceptible" lambs were obtained by treating with long-acting corticoids to depress the resistance of lambs. The establishment rate of worms and their egg-laying capacities were highly reduced in resistant lambs compared with susceptible ones. It can be assumed that the experimental design of infection apparently mimicked well the differences observed between genotypically resistant and susceptible sheep. To assess the adaptation, resistant, susceptible and naive lambs were infected with the two $H$. contortus lines, previously reproduced in resistant or susceptible sheep. The hosts were genetically related lambs (monozygotic twin lambs, within-litter brothers) allocated in an experimental plan designed to enhanced the power of the experiment.
\end{abstract}

* Correspondence and reprints

E-mail: aumont@tours.inra.fr 
The use of monozygotic twins did not prove as useful as expected for parasitological data. There was no significant difference between the life-traits of the two lines. $H$. contortus did not seem to adapt to the resistance status of the host. Therefore, it was considered that selection for resistant sheep was possible with a limited risk of adaptation of the nematode parasites, although long-term monitoring of nematode adaptation should be scheduled if host selection is planned.

Haemonchus contortus / sheep, monozygotic / adaptation / resistance

Résumé - Évolution des traits de vie des strongles gastro-intestinaux en réponse à la résistance de l'hôte : essai d'une approche expérimentale sur un modèle Haemonchus contortus - agneaux "Black Belly". L'utilisation d'animaux plus résistants aux strongles gastro-intestinaux dans les nouvelles pratiques d'élevage peut constituer une pression de sélection significative induisant une adaptation des traits de vie des parasites. Il est donc nécessaire, avant d'intégrer le caractère de résistance dans des programmes de sélection, de s'assurer de l'absence d'adaptation du nématode. L'objectif de cette étude était de déterminer si Haemonchus contortus présentait la capacité d'adapter ses traits de vie à des ovins plus résistants. Un isolat synthétique d'Haemonchus contortus a été créé à partir d'isolats de cinq régions de Guadeloupe (French West Indies), en s'assurant de sa bonne représentativité sur la base de caractères morphométriques et d'isoenzymes. Cet isolat a été multiplié durant 10 générations chez des ovins à statut de résistance très différent. Des agnelles primoinfestées âgées de 6-8 mois, de génotype Black Belly connu pour sa résistance aux strongles gastro-intestinaux, ont été utilisées comme hôtes résistants. Des agnelles, immuno-déprimées par injections de corticoïdes retard ont été utilisées comme hôtes sensibles. Le taux d'installation et la production journalière d'SSufs des parasites ont été très fortement diminués par passage chez les hôtes résistants. L'adaptation des deux lignées d' $H$. contortus a été évaluée par infestation expérimentale de 60 agneaux des deux sexes, répartis en trois groupes : agneaux rendus résistants, agneaux naïfs et agneaux rendus sensibles. Ces animaux, dont neuf couples de jumeaux monozygotes, issus de parents génétiquement très proches (pleins frères issus de parents très apparentés, jumeaux monozygotes), ont été répartis dans les groupes afin de maximiser la probabilité de mettre en évidence des différences entre lignées. La variabilité entre jumeaux homozygotes n'a pas été significativement diminuée pour les variables parasitaires. Malgré la puissance du dispositif expérimental mis en place, aucune différence dans les traits de vie des deux lignées d' $H$. contortus n'a pu être mise en évidence. La sélection d'animaux résistants peut donc être engagée sans risque important d'adaptation d' $H$. contortus dans un premier temps, dans l'attente d'une vérification plus approfondie sur le terrain.

Haemonchus contortus / ovins, monozygotes / adaptation / résistance

\section{INTRODUCTION}

In keeping with formal evolutionary theory, one can distinguish phenotypic selection, which is the change in the phenotypic distribution of a trait within 
a generation, from evolutionary response, which is a change in the distribution of a heritable trait across generations [5]. There is a broad theoretical agreement that reciprocal selection is a precondition for host-parasite coevolution, although few experimental data are available [17]. Breeding for resistance to strongyle nematodes has been intensively studied in sheep and goats (among others: $[30,39,53,54,56,58,59]$ ) but little attention has been paid to the possible consequences of host-parasite co-evolution when selecting for host resistance [11]. The few available strongyle nematode data are contrasted: no adaptation of Haemonchus contortus was recorded by Albers and Burgess [4] and Woolaston and Eady [61] in resistant sheep hosts, whereas several $H$. contortus [24] and Trichostrongylus colubriformis [57] life-traits could evolve during repeated maintenance in susceptible or resistant hosts. The only certain evidence is that hosts can be selected to resist strongyle nematodes and that these nematodes are able to change genetically $[13,27]$ or ecologically [15] when maintained under laboratory conditions. Any experimental study of strongyle nematode maintained under selective pressure of resistant hosts will have to cope with the possible evolution of the nematodes maintained under laboratory conditions. This will not cast light on the host-parasite coevolution which has been clearly described in real life [18], and it will not enlighten their underlying mechanisms [44]. Before studying co-evolution, much remains to be elucidated concerning the influence of susceptibility or resistance of the host on the modification of parasite nematode populations. This is the main trust of the present paper.

Haemonchus contortus is the most widespread nematode parasite of sheep and goats in the warm climates. It causes large production losses in the tropics $[7,23]$ and anthelmintic resistance has developed rapidly in $H$. contortus (among others: $[12,43,55]$ ). Therefore, the need for integrated methods is commonly claimed as a response to an efficient and environmentally casting control of these parasites, including grazing management, biological control and the use of genetically resistant animals $[9,58]$.

The resistance of hosts exerts a strong selective pressure on nematode populations, since the establishment rate might range between 4 to $50 \%$ in $H$. contortus for resistant and susceptible sheep, respectively [6]. It might result in an adaptation of the parasite. Therefore, the potential adaptation of this nematode to a new resistance status of the host has been considered as a preliminary question before breeding for resistance. Nevertheless, this putative adaptation of Heamonchus to resistance status has been little studied and is still debated [58]. In fact, the contrast in the few recorded results in literature depends on: a) the type of parasite, b) the experimental approach or the definition of the resistance status, c) the life-trait used as the phenotypic expression of the adaptation.

Haemonchus contortus is either morphologically [49] genetically [13] or ecologically highly variable [33]. It seems that Haemonchus, due to its high diversity, its ability to adapt to life cycle constraints and its high fecundity rate, is a 
rather good candidate for a possible adaptation to the resistance enhancement of the host. Fleming [24] showed that $H$. contortus can evolve during its repeated multiplication in periparturient susceptible ewes. Surprisingly, no adaptation of Haemonchus was recorded by Albers and Burgess [4] and Woolaston and Eady [61] in resistant lambs. These discrepancies might be due to different measurements of resistance in the above mentioned studies: lambs selected for resistance [60], susceptible periparturient ewes [24], immune-depressed animals by means of corticosteroids injection [4] that inhibits general immune response to helminth infection and suppress differences between genetically different lines of sheep. The resistance to infection has been defined as the ability of the animal to limit the establishment of worms or their propagule production and it involves the immune responses [28]. Faecal egg count (FEC) has been widely used in selecting sheep or goats resistant to $H$. contortus because it is non-destructive, easy to measure and heritable [9,38,45]. Most of studies on related resistance are limited to the egg excretion of nematodes and do not permit evaluation of other life-traits. Fleming [24] showed that both establishment rate and female fecundity of $H$. contortus evolved during repeated reproduction in periparturient ewes. The higher resistance of tropical local breed of sheep resistant to Haemonchus is related to a lower establishment rate $[6,19,25]$. Endoparasite adaptation is frequently the result of several life-trait modifications $[42,52]$ and a measurements of nematode adaptation to the resistance of hosts should be based on several life-traits.

A research programme on genetic resistance to nematode infection has been carried out since 1992 in the French West Indies (FWI) regarding Creole meat goats in Guadeloupe [39], and hair sheep in Martinique. In both host species, $H$. contortus is the major parasite in the FWI. Its adaptation to a more resistant host is being while investigated in both species. The present study was designed to obtain a rapid answer, while minimising bias due to origin of the isolate, maximising the range in resistance status of the host, suppressing interactions between parasitic and free-living traits of life, and increasing the efficiency of the experimental design to detect between-isolate differences in the parasite.

The first step has been already published by Saulai et al. [49] and the other steps are detailed in Saulai [48]. The choice of nematode isolate to test adaptation is critical. $H$. contortus is highly variable even in small areas (proportions of female morphotypes in New Zealand [41]; genetic diversity as assessed from allozymes in Guadeloupe-FWI [49]). We created a new assemblage of isolates in Guadeloupe, the aim being to obtain a synthetic strain that could represent the set of variability in the farms of FWI. One could assume that the effect of acclimation to the laboratory conditions would be minimised with a recent assemblage of isolates and that the set of original variability would be maintained as several isolates were used. This was a reasonable hypothesis considering the genetic, morphological and morphometric data from the five isolates of FWI and the resulting synthetic strain we used [49]. The isolates differed slightly and the synthetic strain was intermediate. It was also shown 
that this synthetic isolate has similar life-traits (pre-patent period, establishment rate, fitness) than another isolate of $H$. contortus from Cuba, ensuring its reliability as regards to other tropical Caribbean isolates [31].

A second step was to select the synthetic strain in resistant and susceptible sheep, using primary infected ewe lambs treated with anthelmintic as resistant lambs, and immune-depressed lambs with long-acting corticosteroids as susceptible hosts. We expected to obtain "resistant" and "susceptible" lines of nematode. This experimental model was chosen to achieve good reproducibility over a large range of resistance status between hosts. A third step consisted in evaluating $H$. contortus resistant or susceptible lines in test lambs (susceptible, standard and resistant ones). These test lambs were either related lambs or monozygotic twin lambs, the latter requiring a more demanding preparation. The present paper reports on the second and third steps methodology based on the results obtained.

\section{MATERIALS AND METHODS}

\subsection{Evolution of different Haemonchus contortus lines in resistant and susceptible sheep}

\subsubsection{Lambs and parasitological features}

The two lines of $H$. contortus were obtained by repeated maintenance of the life cycle of the synthetic isolate created previously, in resistant and susceptible lambs. The 4- to 8-months old ewe-lambs belonged to a local black belly breed (Martinik) and were reared indoor. They were drenched orally, 6-8 days before experimental infection, with Ivermectine, Levamisole and Niclosamide (Yomesane ${ }^{\circledR}$ ) at the manufacturer's recommended dose, to remove any infection. The ewe-lambs were then divided into two groups. The lambs of the first group (named R, resistant) were primary infected with 4500 infective larvae (L3) given on three successive days (13500 L3 in total) at days 0, 1, 2 post - infection (dpi). The lambs of the second group (named S, susceptible) remained uninfected until final infection. These later lambs were immunedepressed 2 days before infection with a lastingly active ( 5 to 6 weeks) corticosteroid (Triamcinolone Acetonide: Kenacort ${ }^{\mathrm{R}} 80 \mathrm{mg}$ per animal). Finally, hosts of both groups were orally infested by $5000 \mathrm{~L} 3$ of their assigned $H$. contortus line. Note that in the first generation, lambs were infected daily with 1500 L3 for 15 days to mimic a natural infection, and the establishment rate was as low as $2.5 \%$ and $0.96 \%$ in the $\mathrm{R}$ and $\mathrm{S}$ groups, respectively. This mode of infection exerted a too drastic selection on nematode lines, possibly due to the natural resistance of Martinik lambs. Too few worms were recovered, which did not allow the measurement of life-traits and the maintenance of such a line. Thus the mode of infection was changed at the 2 nd generation of evolution. For each infection, the larvae of the previous generation were pooled within 


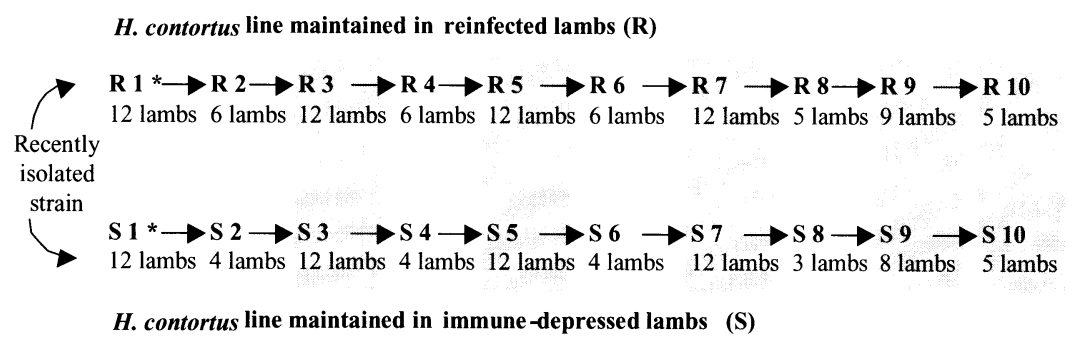

Measures of $H$. contortus Lifetraits and host response

Figure 1. Evolution protocol of Haemonchus contortus lines maintained in immunesuppressed or primary infected (re-infected) lambs.

each $H$. contortus line. This procedure was repeated 10 times (as described in Fig. 1). H. contortus life-traits were evaluated in 6-to 8-months old ewe-lambs in generations $1,3,5,7,9$ and 10 . Generations 2, 4, 6 and 8 were reproduced in 4-to -6 months old ewe-lambs. The number of lambs in each group is shown in Figure 1.

\subsubsection{Host responses and life-traits}

The development of eggs into L3 infective larvae was achieved by cultivation in Earle medium using a modified technique from Hubert and Kerboeuf [32]. The rate of development rate of eggs into larvae was assessed on 10000 20000 eggs in each culture; 4 cultures per day and per lamb were performed for 3 days. The age of L3 used for infection ranged from 3 to 6 weeks. Establishment rates were estimated by worm counts at necropsy on $42 \mathrm{dpi}$ of the lambs. Adult worms, juveniles and 4th stage larvae were counted on a $1 / 10$ aliquot of abomasal contents. The inhibited 4 th stage larvae were extracted from mucosae after peptic digestion for $12 \mathrm{~h}$ at $37^{\circ} \mathrm{C}$. The fecal egg count (FEC) was determined daily from 16 to $23 \mathrm{dpi}$ and twice a week from 28 to $42 \mathrm{dpi}$, according to a modified McMaster technique using centrifugation in sodium chloride solution [8]. Daily egg output (DEO) was monitored twice weekly from Day 23 up to Day 42 pi. Female fecundity was estimated daily by the ratio of DEO during the week before necropsy to the number of females at necropsy. The fitness index (FI) was defined as the ratio of viable L3 output/L3 infective dose; the viable L3 output was based on DEO, egg hatching and larval development. This FI was assessed 6 times between Day 20 pi and Day 42 pi or globally (GFI) over the whole patent period, from Day 21 to 42 pi. Responses of hosts to infection were assessed weekly by eosinophilia (EOSI) as described by Dawkins et al. [22].) 


\subsubsection{Data analyses}

The effect of selection generation, Haemonchus line, their interactions and the contrast in PP, GFI and worm population examination were analysed using the General Linear Model (SAS/STAT, [47]), after log transformation when required. In these latter cases, least square means are given after back transformation. Time repeated data (FEC, DEO, EOSIFI, FI) were analysed by means of the mixed model with the repeated time option by SAS/STAT software package (SAS/STAT, [47]).

\subsection{Test of evolution of the selected "resistant" and "susceptible" lines of $H$. contortus in resistant, standard or susceptible lambs}

\subsubsection{Lambs and parasitological features}

The fitness of the two lines of $H$. contortus created previously were compared by experimental infection of sheep as genetically related as possible 6-to 8month-old black Belly lambs. Monozygotic twin lambs were prepared according to Chesné et al. [16]. The embryos were collected from six ewes (four of them were monozygotic twin lambs) mated by three rams and transferred to 24 receiver dams after bisection. The unfertilised ewes and 19 other ewes were mated 3 weeks later by four other sires. All the offspring either obtained by the embryo transfer (43) or additionally by natural fertilisation (17) were used. Nine pairs of monozygotic twins were available at 6 months of age. The rearing conditions and resistance status preparation were achieved as in trial 1. Lambs were allocated in the $2 \times 2 \times 3$ experimental plan: two sexes, two $H$. contortus lines (susceptible line (SL), resistant line (RL)), three types of lambs: naive lambs (N), immune-depressed (IS) and previously primary infected lambs (PI). Lambs of both genders were equally allocated between-groups IS, N and PI. Twins were allocated between groups to maximise between line contrasts using Pest software [29], which take into account grand-mother, grand-father, father and mother. The most efficient allocation of lambs was: six twins in resistant lamb group, two twins in naive group and one twin in susceptible group (Tab. I).

\subsubsection{Life-traits and data analyses}

Life-traits were determined and analysed as previously described. However, the model used was more complex, taking into account Haemonchus line factor, lamb group factor, sex factor, first- and second-order interactions. To estimate the volume of monozygotic twins in parasitological data sets, variations in performances and life-traits were determined between non-twin lambs, between twin lambs and within pairs of twin lambs, after adjustment for the effects of the experimental plan. 
Table I. Distribution of monozygotic twin lambs in the experimental plan designed for testing of between-line differences in life-traits of Haemonchus contortus in isolates previously maintained in susceptible or resistant lambs during 10 generations.

\begin{tabular}{llcc}
\hline Host groups & $\begin{array}{l}\text { Gender of } \\
\text { animals }\end{array}$ & $\begin{array}{c}\text { Line maintained in } \\
\text { resistant host (RL) }\end{array}$ & $\begin{array}{c}\text { Line maintained in } \\
\text { susceptible host (SL) }\end{array}$ \\
\hline $\begin{array}{l}\text { Resistant (prime } \\
\text { infected previously) }\end{array}$ & Ram lamb & $2 \mathrm{Mt}+3 \mathrm{M}$ & $2 \mathrm{Mt}+3 \mathrm{M}$ \\
& Ewe lamb & $4 \mathrm{Ft}+1 \mathrm{~F}$ & $4 \mathrm{Ft}+1 \mathrm{~F}$ \\
\hline Naive & Ram lamb & $1 \mathrm{Mt}+4 \mathrm{M}$ & $1 \mathrm{Mt}+4 \mathrm{M}$ \\
& Ewe lamb & $1 \mathrm{Ft}+4 \mathrm{~F}$ & $1 \mathrm{Ft}+4 \mathrm{~F}$ \\
\hline $\begin{array}{l}\text { Susceptible (Immune } \\
\text { depressed) }\end{array}$ & Ram lamb & $5 \mathrm{M}$ & $5 \mathrm{M}$ \\
\hline
\end{tabular}

Mt: monozygotic twin ram lambs; Ft: monozygotic twin ewe lambs; $\mathrm{M}$ and $\mathrm{F}$ : non-monozygotic ram and ewe lambs.

\section{RESULTS AND DISCUSSION}

\subsection{Evolution of Haemonchus contortus life-traits maintained in immune-depressed or vaccinated lambs during 10 generations}

\subsubsection{Is the evolution model reliable in terms of biological significance?}

The experimental design used was set up to create the most reproducible range in host resistance status. The lambs used were highly resistant: i) black belly sheep is known to be more resistant to helminth infection particularly by Haemonchus, than other tropical or exotic breeds [20,62], ii) ewe lambs are known to be more resistant than ram lambs $[10,35,63]$, particularly in the Martinik black belly sheep [36]. The prime infection till 4 months induced a marked increase in resistance $[1,6]$. Therefore, it can be assumed that the most resistant sheep available in the FWI were used.

It was shown in sheep that corticosteroid treatment inhibits between-breed differences in helminth resistance [46], and decreases immunological response after prime infection by $H$. contortus [2] or cross-immune response of lambs infected with different Trichostrongyles [40]. In our experiment, the corticosteroid injection dramatically inhibited eosinophilia response to $H$. contortus infection up to the 35th dpi confirming the results [40] (Fig. 2). It increased the FEC (geometric means) by 12-to 317-fold compared to the primary infected group, depending on the generation (Tab. II). However, it must be emphasised that, for practical reasons, hosts with very low DEO in resistant lines (e.g. the most resistant hosts) were not used for preparation of L3 for the next generation, decreasing the selection pressure. The differences in FEC between susceptible and resistant hosts were considerably greater than those 
Table II. Estimated means of life-traits of 2 lines of $H$. contortus maintained in immune-suppressed or re-infected lambs during 10 generations. Life-traits were estimated during the repeated passages in the assigned hosts.

\begin{tabular}{|c|c|c|c|c|c|c|c|}
\hline & $\mathbf{P P}$ & $\begin{array}{c}\text { FEC }^{*} \\
\left(\mathrm{egg} \cdot \mathrm{g}^{-1}\right)\end{array}$ & $\left.\begin{array}{c}\text { DEO* } \\
(\text { egg.d } \\
-1\end{array}\right)$ & $\begin{array}{c}\mathbf{F y} \\
\left(\mathrm{e} \cdot \mathbf{d}^{-1} \cdot \mathrm{fem}\right)\end{array}$ & $\begin{array}{l}\text { DR } \\
\text { (\%) }\end{array}$ & $\begin{array}{c}\mathbf{F I}^{*} \\
\left(\mathbf{d}^{-1}\right)\end{array}$ & $\begin{array}{c}\text { ER* } \\
\text { All } \\
\text { stages }\end{array}$ \\
\hline \multicolumn{8}{|l|}{ Line } \\
\hline Maintained on S lambs (SL) & $18 a$ & $8962 a$ & $3485495 a$ & 4166 & 65.7 & $593 a$ & $33.3 a$ \\
\hline Maintained on $\mathrm{R}$ lambs (RL) & $26 b$ & $211 b$ & $94684 b$ & 3373 & 64.8 & $173 b$ & $7.7 b$ \\
\hline \multicolumn{8}{|l|}{ Worm Generation - Gn } \\
\hline Gn3 & $20 a$ & $5356 a$ & $2651607 a$ & $6142 a$ & $76.7 a$ & $748 a$ & $33.6 a$ \\
\hline Gn5 & $22 b$ & $1746 b$ & $779230 \mathrm{~b}$ & $4032 a$ & $65.2 c$ & $377 c$ & $20.4 b c$ \\
\hline Gn7 & $22 b$ & $2394 c$ & $1095273 b$ & $4627 a$ & $71.8 b$ & $544 b$ & $26.2 a b$ \\
\hline Gn9 & $22 b$ & $1045 d$ & $387918 c$ & $3884 a$ & $56.1 d$ & $274 d$ & $14.6 \mathrm{~cd}$ \\
\hline Gn10 & $24 b$ & $227 e$ & $73970 d$ & $1299 b$ & $56.5 d$ & $47 e$ & $7.6 d$ \\
\hline \multicolumn{8}{|l|}{ Line $\times$ generation } \\
\hline $\mathrm{SL}, \mathrm{Gn} 3$ & $18 a$ & $18328 a$ & $6906992 a$ & 6126 & 77.2 & $1274 a$ & 47.9 \\
\hline $\mathrm{RL}, \mathrm{Gn} 3$ & $21 b$ & $1557 c$ & $1016250 d$ & 6158 & 76.2 & $409 e$ & 19.4 \\
\hline SL, Gn5 & $18 a$ & $9854 b$ & $3877250 b$ & 3528 & 64.4 & $533 c$ & 32.4 \\
\hline RL, Gn5 & $27 \mathrm{~cd}$ & $299 d$ & $153736 e$ & 4582 & 66.1 & $254 f$ & 8.4 \\
\hline SL, Gn7 & $18 a$ & $14932 a$ & $5725578 a b$ & 4761 & 70.6 & $1076 b$ & 43.7 \\
\hline RL, Gn7 & $26 c$ & $373 d$ & $206579 e$ & 4495 & 72.9 & $233 \mathrm{f}$ & 8.6 \\
\hline SL, Gn9 & $17 a$ & $8423 b$ & $3160693 b c$ & 4398 & 58.9 & $547 c$ & 27.8 \\
\hline RL, Gn9 & $27 c d$ & $118 e$ & $44152 f$ & 3411 & 53.3 & $101 d$ & 1.5 \\
\hline SL, Gn10 & $19 a$ & $2539 c$ & $1059554 \mathrm{~cd}$ & 2586 & 57.3 & $105 d$ & 14.6 \\
\hline RL, Gn10 & $32 d$ & $8 f$ & $1287 \mathrm{~g}$ & 373 & 55.7 & $0 \mathrm{~g}$ & 0.5 \\
\hline
\end{tabular}

PP: prepatent period; FEC: Fecal Egg count from 21 to 42 dpi; DEO: Daily Egg Output from 21 to 42 dpi; Fy: fecundity of female parasite at $42 \mathrm{dpi}$; DR: development rate of eggs in infective larvae; ER: establishment rate for all worms or in adult.

Means with different letters are significantly different at $P<0.05$.

* Back transformed. 
a)

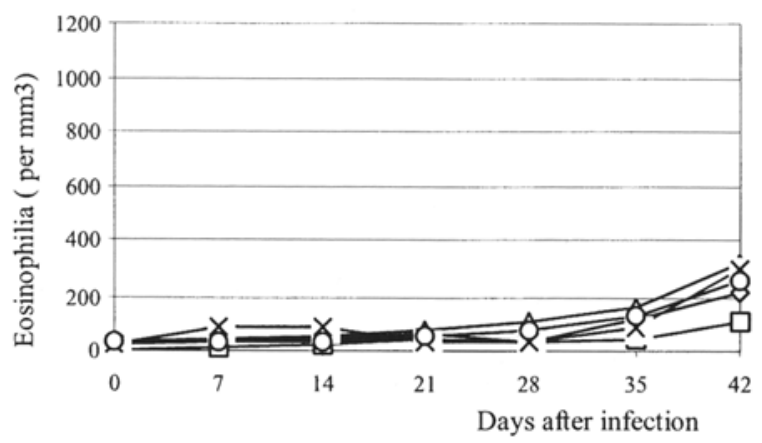

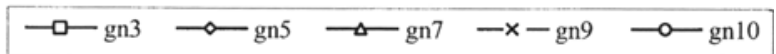

b)

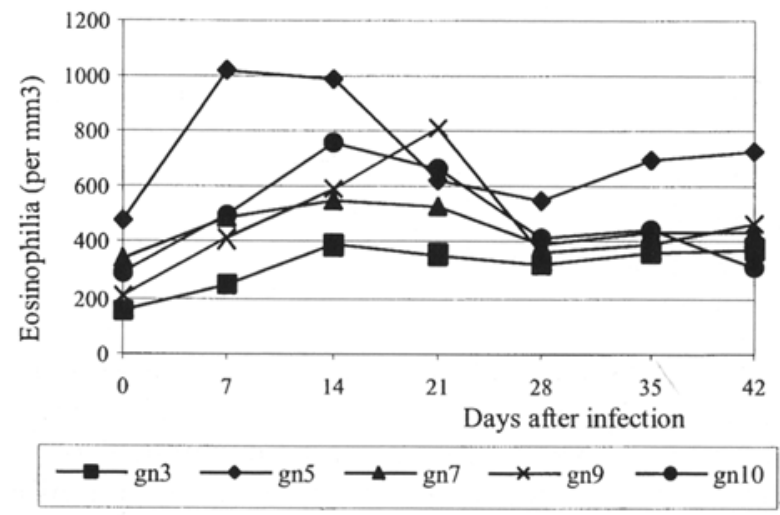

Figure 2. Estimated means (back transformed) of eosinophilia in immunesuppressed (a) and re-infected (b) lambs infected with different generations (gn 3 to gn 10) of Haemonchus contortus isolates.

recorded in Australia by Woolaston et al. [59] in sheep lines selected for either susceptibility or resistance to Haemonchus. The establishment rate of larvae (all worms present) in the $\mathrm{S}$ group was 6-fold higher than in the $\mathrm{R}$ group, for all generations (Tab. II). The prepatent period (PP) in the $\mathrm{S}$ group was 8 days shorter than in the $\mathrm{R}$ group (Tab. II). There was no difference in female fecundity and egg development rates between the two groups. The geometric mean fitness index was significantly higher in the $\mathrm{S}$ group than in the R group, largely due to marked between-group differences in DEO. 
Table III. Standard deviation of animal performances and parasitological data between all animals, between monozygotic twin couples and within monozygotic twin couples. Reduction variance due to monozygotic twins is given in variance ratio between: within couples.

\begin{tabular}{|c|c|c|c|c|c|c|}
\hline & \multicolumn{3}{|c|}{ Animal performances } & \multicolumn{3}{|c|}{ Parasitological data } \\
\hline & $\begin{array}{l}\mathrm{WW} \\
(\mathrm{kg})\end{array}$ & $\begin{array}{l}\text { W5m } \\
(\mathrm{kg})\end{array}$ & $\begin{array}{c}\text { BWG } \\
\left(\mathrm{g} \cdot \mathrm{d}^{-1}\right)\end{array}$ & $\begin{array}{c}\text { Worm } \\
*\end{array}$ & $\begin{array}{c}\mathrm{Fy}^{*} \\
\left(\mathrm{Egg} \cdot \mathrm{d}^{-1}\right)\end{array}$ & FIT $^{*}$ \\
\hline Between all animals -B & 3.99 & 5.02 & 40 & 0.89 & 0.64 & 0.63 \\
\hline $\begin{array}{l}\text { Between monozygotic } \\
\text { twin couples }\end{array}$ & 1.10 & 2.35 & 16 & 0.86 & 0.44 & 0.57 \\
\hline $\begin{array}{l}\text { Within monozygotic } \\
\text { twin couples, W }\end{array}$ & 0.41 & 1.32 & 6 & 0.75 & 0.52 & 0.34 \\
\hline Variance ratio $\mathrm{B}: \mathrm{W}$ & 7.10 & 3.17 & 5.96 & 1.31 & 0.73 & 2.86 \\
\hline
\end{tabular}

WW: Weaning weight; W5m: Weight at 5 months old; BWG: Body Weight Gain before weaning.

Worm: Worm count, FY: Fecundity of female parasite; FIT: Fitness from 21 to 42 dpi.

* $\log$ transformed. When variable was log transformed, variance ratio is computed on transformed variable.

Therefore, it can be assumed that $H$. contortus lines were maintained under largely different host responses. These highly marked differences in selection pressure might compensate for the relatively low number of generations $(n=$ 10). The selection pressure was really effective on the establishment rate. The fitness index (600 L3/d/L3 ingested) and the fecundity (5400-6000 eggs per day and per female) of $H$. contortus that were recorded for an oral dose of 5000L3 in the first generations (Tab. III) are reliable and similar to that recorded elsewhere particularly by Coyne et al. [21] in a specific study of life-trait. The establishment rate range from $33 \%$ to $8 \%$ in the $\mathrm{S}$ group and the $\mathrm{R}$ group (Tab. II) is similar to that recorded for the same isolate in a between-breed comparison of susceptible breeds of sheep INRA 401 and resistant breed of sheep [6].

\subsubsection{Is the evolution model reliable in terms of diversity?}

The analyses of the generation effects showed that the Haemonchus line in the $\mathrm{S}$ group remained unchanged during the experiment, whereas, the $\mathrm{R}$ line evolved its PP and its establishment rate (Tab. II). These generation effects will be confirmed in an experimental approach by comparing the first generation to the 10th generation of both the $\mathrm{S}$ line and the $\mathrm{R}$ line. 
One would expect a loss of variability (due to genetic drift and/or inbreeding) and adaptation to the selective pressure. This loss of variability has been recorded between Haemonchus species under strong environmental pressure [33] and in Haemonchus contortus lines submitted to anthelmintic pressure [37]. During the course of our experiment, a strong acclimation to laboratory conditions was noticed in RL with a marked decrease in fitness. It possibly masked greater differences between $H$. contortus lines. Acclimation to laboratory conditions has been recorded previously in T. circumcincta [26] and Heligmosomoides polygyrus [15] but was notably more marked in our experiment. The cultivation media used for the egg development might play a role in acclimation. In our experiment, egg development into infective larvae reached $65 \%$ whereas in natural conditions it is often less than 1\% [14], suggesting relaxed experimental conditions. Shabalina et al. [50] observed a strong decrease in Drosophila fitness maintained under relaxed conditions during 10 generations. This highlights the difficult of maintaining task to maintain representative isolates under controlled laboratory conditions, and finally of assessing adaptation.

Therefore, one could assume that the employed experimental design ensured a reproducible and very marked range in resistance of the hosts, without any interactions between the external and internal parts of the cycles. Its reliability might be questionable, essentially in terms of diversity, by reducing genetic variability of parasites due to genetic drift. The experimental design did not strictly protect against genetic drift despite the attention paid to the diversity of the isolates used to create the first generation and the large number of parasites used at each generation. The adaptation of life-traits is likely under polygenic control, decreasing the probability of genetic drift. A repetition of the synthetic strain creation step and the evolution step would be the formal reply to such bias.

\subsection{No life-trait adaptation in the two lines of $H$. contortus maintained in susceptible and resistant lambs}

The principle of the final trial was to place each of two Haemonchus lines in three extreme conditions of resistance to express putative differences due to the adaptation to resistance of the host, i.e. from the immune-depressed host (very susceptible hosts), naive host (no selection pressure) and to the Primary infected ewe lambs of local breed (highly resistant hosts). However, such comparisons require a very homogenous host to be infected by the different Haemonchus lines. Therefore, the final trial was planned with monozygotic twins to obtain the most efficient design showing significant variation between $H$. contortus lines between and within animal groups. The use of monozygotic twins should be an efficient means of increasing the power of the experimental design. 


\subsubsection{What could be expected from the use of monozygotic twins to detect adaptation of $\mathrm{H}$. contortus to resistant hosts?}

As can be expected, the variations within monozygotic pairs of twins in animal performances were significantly lower than between-couple or betweennon-twin variations. However, no significant decrease in variation was found for parasitological variables using monozygotic twin lambs (Tab. III). Despite an optimisation approach in planning the experiment, the monozygotic twin lambs appeared to be of little poor interest for parasitological variables since withincouple variations were similar to between-animal variations of different genetic parents. It should be emphasised that, in our data set, many embryos were issued from highly genetically related lambs, and thus the use of monozygotic twins could not improve extensively the power of our experimental design.

No significant interaction between animal groups and $H$. contortus line factors was found. The final comparison between $H$. contortus lines was achieved with 30 animals per line. To our knowledge, there is no available study involving such numbers of hosts in comparing strains of nematode parasites, except the study of Woolaston et al. [60] who aggregated FEC data obtained over several years.

\subsubsection{No difference in life-traits of the two Haemonchus isolates placed in host of different resistance status}

The animal response (EOSI) and parasitological data (FEC, establishment rate, $\mathrm{PP}$, fecundity of female fitness index) reported in Table IV showed that the different groups of animal were reliable in terms of host response ranking. The allocation of ram lambs and ewe lambs in each group induced a source of variation due to the higher susceptibility of rams compared to ewes. Furthermore, the sex effect was still significant in corticoid in IS group. No difference in life-traits of both $H$. contortus lines was recorded whatever the resistance status of the host. This result confirms the partial results (estimation on FEC only) obtained in sheep infected by $H$. contortus $[3,4,60]$. $H$. contortus adults in friendly climatic conditions have a rapid turn-over and their survival relies mostly on their capacity to produce propagules. These conditions are similar to those encountered in Guadeloupe: the hosts are fairly resistant since $50 \%$ of the offspring dies due to helminth infection before weaning [7]. Climatic conditions are good for efficient development of eggs into larvae throughout the year whatever the season [51]. It can be supposed that the worms were already adapted to the fitness landscape including the resistant host and favourable climatic conditions and would not easily evolve much further. A different result on adaptation could possibly be obtained in situations where lambs would be more susceptible and the environmental climatic conditions harsher. The tradeoffs between parasitic and free-living phases are not yet clearly understood but 
Table IV. Estimated means of life-traits of 2 lines of $H$. contortus maintained in immune-suppressed (SL) or re-infected lambs (RL) during 10 generations. Life-traits are estimated at the same time in animal groups differing in resistance status and sex of lambs.

\begin{tabular}{|c|c|c|c|c|c|c|}
\hline & $\begin{array}{l}\mathbf{P P} \\
\text { (d) }\end{array}$ & $\begin{array}{c}\mathbf{F E C}^{*} \\
\left(\mathrm{egg} \cdot \mathrm{g}^{-1}\right)\end{array}$ & $\begin{array}{c}\text { DEO* }^{*} \\
\left(\mathrm{egg} \cdot \mathrm{d}^{-1}\right)\end{array}$ & $\begin{array}{c}\text { Fy } \\
\left(\mathrm{egg} \cdot \mathrm{d}^{-1} \cdot \mathrm{fem}\right)\end{array}$ & $\begin{array}{c}\mathbf{F I}^{*} \\
\left(\mathbf{d}^{-1}\right)\end{array}$ & $\begin{array}{c}\text { ER* }^{*} \\
\text { All stages }\end{array}$ \\
\hline \multicolumn{7}{|l|}{ Haemonchus line } \\
\hline Maintained on S lambs (SL) & $20.9 a$ & $640 a$ & $436896 a$ & $7155 a$ & $1860 a$ & 9.8 \\
\hline Maintained on R lambs (RL) & $20.5 a$ & $593 a$ & $369293 a$ & $5508 a$ & $1833 \mathrm{a}$ & 8.0 \\
\hline \multicolumn{7}{|l|}{ Gender of lambs } \\
\hline Ram lambs & $18.4 a$ & $1636 a$ & $1152252 a$ & $12697 a$ & $2833 a$ & 12.1 \\
\hline Ewe lambs & $23.4 b$ & $226 b$ & $138133 b$ & $2677 b$ & $1181 a$ & 5.7 \\
\hline \multicolumn{7}{|l|}{ Host resistance status } \\
\hline Immune suppressed (IS) & $17.5 a$ & $5194 a$ & $3245800 a$ & $6058 a$ & $5955 a$ & $20.4 a$ \\
\hline Naive $(\mathrm{N})$ & $19.7 a$ & $262 b$ & $202094 b$ & $8818 a$ & $1207 b$ & $2.5 b$ \\
\hline Prime infected (PI) & $25.8 b$ & $159 b$ & $95304 a$ & $4538 a$ & $789 c$ & $3.8 a$ \\
\hline \multicolumn{7}{|l|}{ Host resistance $\times$ Line } \\
\hline IS, SL & 17.9 & 5435 & 3341425 & 6504 & 6820 & 20.0 \\
\hline IS, RL & 17.1 & 4964 & 3152907 & 5636 & 5197 & 15.0 \\
\hline $\mathrm{N}, \mathrm{SL}$ & 19.5 & 312 & 244866 & 1243 & 1108 & 2.0 \\
\hline $\mathrm{N}, \mathrm{RL}$ & 19.8 & 219 & 166659 & 6110 & 1313 & 2.5 \\
\hline PI, SL & 26.2 & 142 & 98570 & 4253 & 751 & 3.9 \\
\hline PI, RL & 25.5 & 178 & 92142 & 4835 & 829 & 2.6 \\
\hline \multicolumn{7}{|l|}{ Sex of host $\times$ line } \\
\hline IS, ram lambs & 17.0 & 9699 & 5539794 & 10151 & 7872 & 26.2 \\
\hline IS, ewe lambs & 18.0 & 2779 & 1900964 & 3344 & 4494 & 2.2 \\
\hline $\mathrm{N}$, ram lambs & 17.6 & 333 & 274340 & 14113 & 1268 & 5.9 \\
\hline $\mathrm{N}$, ewe lambs & 22.0 & 205 & 148567 & 5263 & 1148 & 10.7 \\
\hline PI, ram lambs & 20.7 & 1315 & 996695 & 14216 & 2154 & 2.2 \\
\hline PI, ewe lambs & 32.2 & 8 & 5449 & 636 & 216 & 1.0 \\
\hline
\end{tabular}

PP: pre-patent period; FEC: Fecal Egg count from 21 to 42 dpi; DEO: Daily Egg Output from 21 to 42 dpi; Fy: Fecundity of female parasite at $42 \mathrm{dpi}$; ER: Establishment rate for all worms or in adult.

Means with different letters are significantly different at $P<0.05$.

* Back transformed. 
they might play a role in the understanding of the adaptation of nematode parasites: Jorgensen et al. [34] reported that eggs excreted by worms of different Trichostrongyle species established in resistant hosts developed less than those established in susceptible ones.

\section{GENERAL CONCLUSION}

The ability of a parasite to adapt its life-traits to an enhancement of host resistance is a preliminary question to solve before running a breeding programme including the helminth resistance trait. The question is complex and depends on the type and the diversity of the parasite and on the intensity of the resistance. Different approaches reported in the literature have given contrasting results. We chose a three-step experimental approach: creation of Haemonchus isolate representative of the diversity of the parasite in the region concerned (the Caribbean), repeated passage in resistant and susceptible lambs to reproduce marked and repeatable differences in resistance status of the host, comparing different life-traits of the evolved $H$. contortus lines in highly genetically related hosts of different resistance status. The artificial manipulation of host status was efficient despite some putative artefacts due to a direct effect of corticosteroid on the biology of parasite. The major bias was the possible occurrence of genetic drift. This was overcome during selection by using hosts that were partly resistant, and by rejecting those that presented highest resistance, for practical reasons (they did not excrete many eggs). Such a hypothesis - genetic drift is also unlikely since fitness and its components are probably polygenic traits. The other limit of the study is the few passages during evolution of the parasite. Finally, the use of monozygotic twins in parasitological studies with $H$. contortus appeared to be of limited interest since within-pair variability was not significantly lower than general variability.

As a preliminary response to geneticists in charge of breeding programmes of small ruminants in the Caribbean, one could assume that the use of resistant animal would not lead to an adaptation of Haemonchus until a long time, confirming referenced studies on the topics, keeping up to previous records on absence of adaptation of the parasite. However, these results have to be confirmed under field conditions after a real enhancement of host resistance established over a long period. 


\section{ACKNOWLEDGEMENTS}

Thanks are due to the "Bureau des ressources génétiques" for its financial support. The additional facilities provided by the INRA Departments of Animal Health, Animal Genetics and Animal Physiology are acknowledged. The PhD grant of M. Saulai was funded by the Guadeloupe Region and the "ministère de l'Éducation Nationale de la Recherche et de la Technologie". Technical assistance of H. Varo and P. Despois was greatly appreciated. Our friendly thanks to Y. Cognié and P. Chesné in preparing monozygotic twin lambs.

\section{REFERENCES}

[1] Adams D.B., Beth K.J., Immunity acquired by sheep from an experimental infection with Haemonchus contortus, Int. J. Parasitol. 16 (1981) 659-664.

[2] Adams D.B., Developmental arrest of Haemonchus contortus in sheep treated with corticosteroid, Int. J. Parasitol. 12 (1982) 523-529.

[3] Adams D.B., Infection with Haemonchus contortus in sheep and the role of adaptive immunity in selection of the parasite, Int. J. Parasitol. 18 (1988) 1071-1075.

[4] Albers G.A.A., Burgess S.K., Serial passage of Haemonchus contortus in resistant and susceptible sheep, Vet. Parasitol. 28 (1988) 303-306.

[5] Arnold S.J., Wade M.J., On the measurement of natural and sexual selection: applications, Evolution 38 (1984) 720-734.

[6] Aumont G., Gruner L., Hostache G., Comparative resistance of Black Belly vs. INRA401 sheep to Haemonchus contortus, Acta Parasitol. 45 (2000) 221.

[7] Aumont G., Pouillot R., Simon R., Hostache G., Barré N., Varo H., Parasitisme digestif des petits ruminants dans les Antilles françaises, INRA Prod. Anim. 10 (1997) 79-90.

[8] Aumont G., Barré N., Mandonnet N'Zobadila G., Ouattata L., Vassiliades G., Strongyloses gastro-intestinales des petits ruminants en milieu tropical: résistance génétique et milieu d'infestation. Rapport annuel de l'ATP MIPA 72/94. Résultats de l'année 1996, Unité de Recherches Zootechniques, Guadeloupe, 1997.

[9] Baker R.L., Genetics of disease resistance in small ruminants in Africa, in: Gray G.D., Woolaston R.R., Eaton B.T. (Eds.), Breeding for resistance to infectious diseases in small ruminants, ACIAR, Camberra, 1995, pp. 119-138.

[10] Barger I.A., Influence of sex and reproductive status on susceptibility of ruminants to nematode parasitism, Int. J. Parasitol. 23 (1993) 463-469.

[11] Barger I.A., Sutherst R.W., Population biology of host and parasite, in: Gray G.D. Woolaston R.R. (Eds.), Breeding for disease resistance in sheep, Aust. Wool Corp., Melbourne, 1991, pp. 51-56.

[12] Barre N., Amouroux I., Aprelon R., Samut T., Résistance des strongles gastrointestinaux aux anthelmintiques dans les élevages caprins en Guadeloupe (Antilles françaises), Rev. Élev. Med. Vet. Pays Trop. 50 (1997) 105-110. 
[13] Bentounsi B., Cabaret J. Analysis of helminth genetic data: comparative examples with Haemonchus contortus isozymes using exact-tests or resampling procedures, Parasitol. Res. 85 (1999) 855-857.

[14] Berbigier P., Gruner L., Mambrini M., Sophie S.A., Faecal water content and egg survival of goat gastrointestinal strongyles under dry tropical conditions in Guadeloupe, Parasitol. Res. 76 (1990) 379-385.

[15] Chehresa A., Beech R.N., Scott M.E., Life history variation among lines isolated from a laboratory population of Heligmosomoides polygyrus bakeri, Int. J. Parasitol. 27 (1997) 541-555.

[16] Chesné P., Colas G., Cognié Y., Guérin Y., Sévellec C., Lamb production using superovulation, embryo bisection, and transfer, Theriogenology 27 (1987) 751-757.

[17] Clayton D.H., Lee P.L.M., Tomkins D.M., Brodie I.E.D., Reciprocal natural selection on host-parasite phenotypes, Am. Nat. 154 (1999) 261-270.

[18] Coltman D.W., Pilkington J.G., Smith J.A., Pemberton J.M., Parasite-mediated selection against inbred Soay sheep in a free-living, island population, Evolution 53 (1999) 1259-1267.

[19] Courtney C.H., Parker C.F., McClure K.E., Herd R.P., Resistance of exotic and domestic lambs to experimental infection with Haemonchus contortus, Int. J. Parasitol. 15 (1985) 101-109.

[20] Courtney C.H., Parker C.F., McClure K.E., Herd R.P., A comparison of the periparturient rise in faecal egg counts of exotic and domestic ewes, Int. J. Parasitol. 14 (1984) 377-381.

[21] Coyne M.J., Smith G., Johnstone C., A study of the mortality and fecundity of Haemonchus contortus in sheep following experimental infections, Int. J. Parasitol. 21 (1991) 847-853.

[22] Dawkins H.J.S., Windon R.G., Eagleson G.K., Eosinophil responses in sheep selected for high and low responsiveness to Trichostrongylus colubriformis, Int. J. Parasitol. 18 (1989) 199-205.

[23] Fabiyi J.P., Production losses and control of helminths in ruminants of tropical regions, Int. J. Parasitol. 17 (1987) 571-578.

[24] Fleming MW., Selection for a strain of Haemonchus contortus that exhibits periparturient egg rise in sheep, J. Parasitol. 79 (1993) 399-402.

[25] Gamble H.R., Zajac A.M., Resistance of St Croix lambs to Haemonchus contortus in experimentally and naturally acquired infection, Vet. Parasitol. 41 (1992) 211-225.

[26] Gasnier N., Cabaret J., Stable and unstable environments influence the genetic diversity of the nematode Teladorsagia circumcincta, a parasite of small ruminants, Parasitol. Res. 84 (1998) 676-681.

[27] Gasnier N., Cabaret J., Moulia C., Allozyme variation between laboratory reared and wild populations of Teladorsagia circumcincta., Int. J. Parasitol. 22 (1992) 581-587.

[28] Gill H.S., Gray G.D., Watson D.L., Husband A.J, Specific antibody responses to Haemonchus contortus in genetically resistant sheep, Parasite Immunol. 15 (1993) 61-67.

[29] Groeneveld E., PEST User's manual. Institut für Tierzucht und Tierverhalten, FAL, Neustadt, 1994. 
[30] Gruner L., Lantier F., Breeding for resistance to infectious diseases of small ruminants in Europe, in: Breeding for resistance to infectious diseases in small ruminants, Gray G.D., Woolaston R.R., Eaton B.T. (Eds.), Aciar Monograph No. 34 (1995).

[31] Hostache G., Aumont G., Saulai M., Despois P., Depres E., Infection of lambs with two isolates of Haemonchus contortus from the Caribbean, in: Proceedings of the 17th international conference of the WAAVP, Copenhagen, Denmark, C7, 1999,76 .

[32] Hubert J., Kerboeuf D. A new method for culture of larvae used in diagnosis of ruminant gastrointestinal strongylosis: comparison with fecal cultures, Can. J. Comp. Med. 48 (1984) 63-71.

[33] Jacquiet P., Humbert J.F., Comes A.M., Cabaret J., Thiam E., Cheikh D., Ecological, morphological and genetic characterization of sympatric Haemonchus spp. parasites of domestic ruminants in Mauritania, Parasitology 110 (1995) 483-492.

[34] Jörgensen L.T., Leathwick D.M., Charleston W.A.G., Godfrey P.L., Vlassoff A., Sutherland I.A., Variation between hosts in the developmental success of the freeliving stages of trichostrongyle infections of sheep, Int. J. Parasitol. 28 (1998) 1347-1352.

[35] Luffau G., Péry P., Charley J. Réponse immunitaire chez les ovins infestés expérimentalement par Haemonchus contortus. Étude comparative chez le mâle et chez la femelle, Ann. Rech. Vét. 12 (1981) 173-181.

[36] Mahieu M., Aumont G., Michaux Y., Alexandre G., Archimède H., Boval M., Thériez M., L'association d'ovins et de bovins sur des prairies irriguées en Martinique, INRA Prod. Anim. 10 (1997) 55-65.

[37] Maingi N., Scott M.E., Prichard R.K., Effect of selection pressure for thiabendazole resistance on fitness of Haemonchus contortus in sheep, Parasitology, 100 (1990) 327-335.

[38] Mandonnet N., Aumont G., Fleury J., Gruner L., Bouix J., Vu Tien Khang J., Genetic variability in resistance of creole goats to natural infection with Trichostrongylids in Guadeloupe, Ann. New York Acad. Sci. 791 (1996) 421-431.

[39] Mandonnet N., Aumont G., Fleury J., Gruner L., Bouix J., Vu Tien Khang J., Résistance génétique aux strongles gastro-intestinaux chez les caprins créoles. Influence de différents environnement tropicaux sur l'expression du potentiel génétique de résistance, INRA Prod. Anim. 10 (1997) 91-98.

[40] Matthews D., Brundson R.V., Vlassof A., 1979. Effect of dexamethasone on the ability of sheep to resist re-infection with nematodes, Vet. Parasitol. 5 (1979) $65-75$.

[41] Mc Kenna P.B., Morphological evidence of subspeciation in Haemonchus contortus from New-Zealand sheep: the vulval flap formula, N.Z.J. Agric. Res. 14, (1971) 902-914.

[42] Morand S., Life-history traits in parasitic nematodes: a comparative approach for the search of invariants, Funct. Ecol. 10 (1996) 210-218.

[43] Overend D.J., Phillips M.L., Poulton A.L., Foster C.E.D., Anthelmintic resistance in Australian sheep nematode populations, Aust. Vet. J. 71 (1994) 117-121.

[44] Peters A.M., Lively M., The red queen and fluctuating epistasis: a population genetic analysis of antagonistic evolution, Am. Nat. 154 (1999) 393-405. 
[45] Piper L.R., Genetic variation in resistance to internal parasites, in: McGuirk B.J. (Ed.), Merino improvement programs in Australia, Aust. Wool Corp. Sydney, 1987, pp. 351-363.

[46] Presson B.L., Gray G.D., Burgess S.K., The effect of immunosuppression with dexamethasone on Haemonchus contortus infections in genetically resistant merino sheep, Parasite Immunol. 10 (1988) 675-680.

[47] SAS/STAT. User's Guide, Version 6, 4th edn., Vol. 2, Cary, NC, USA, 1998.

[48] Saulai M., Évolution de la fitness de deux lignées d'Haemonchus contortus chez des ovins rendus sensibles ou résistants en conditions expérimentales, Ph.D. Thesis, Paris XIII University, 1999.

[49] Saulai M., Hostache G., Aumont G., Cabaret J., From isolates to laboratory populations: maintenance of variability in the nematode Haemonchus contortus, Parasites 7 (1999) 31-38.

[50] Shabalina S.A., Yampolsky L.Y., Kondrashov A.S., Rapid decline of fitness in panmictic populations of Drosophila melanogaster maintained under relaxed natural selection, Proc. Nat. Acad. Sci. USA 94 (1997) 13034-13039.

[51] Simon R., Aumont G., Aprelon R., Variations in herbage density of third stage larvae of goats strongyle during dry season in Guadeloupe (F.W.I.), Ann. New York Acad. Sci. 791 (1995) 412-420.

[52] Skorping A., Andrew F.R., Keymer A.E., Life history covariation in intestinal nematodes of mammals, Oikos 60 (1991) 365-372.

[53] Sréter T., Kassai T., Takacs E., The heritability and specificity of responsiveness to infection with Haemonchus contortus in sheep, Int. J. Parasitol. 24 (1994) 871-876.

[54] Stears M.J., Bairden K., Bishop C., Buitkamp J., Duncan J.L., Gettinby G., McKellar Q.A., Park M., Parkins J.J., Reid S.W.J., Strain S., Murray M., The genetic basis of resistance to Ostertagia circumcincta in lambs, Vet. J. 154 (1997) $111-119$.

[55] Van Wyk J.A., Malan F.S., Resistance of field strains of Haemonchus contortus to ivermectin, closantel, rafoxanide and the benzimidazoles in South Africa, Vet. Rec. 123 (1988) 226-228.

[56] Watson T.G., Baker R.L., Harvey T.G., Genetic variation in resistance or tolerance to internal nematode parasites in strains of sheep at Rotomahana, Proc. N. Z. Soc. Anim. Prod. 46 (1986) 23-26.

[57] Windon R.G., Genetic control to host responses involved in resistance to gastrointestinal nematodes of sheep, in: Owen J.B., Axford R.F.E. (Eds.), Breeding for disease resistance in farm animals, CAB Int., Wallingford, 1991, pp. 162-186.

[58] Woolaston R.R., Baker R.L., Prospects of breeding small ruminants for resistance to internal parasites, Int. J. Parasitol. 26 (1996) 845-855.

[59] Woolaston R.R., Barger I.A., Piper L.R., Response to helminth infection of sheep selected for resistance to Haemonchus contortus, Int. J. Parasitol. 20 (1990) 1015-1018.

[60] Woolaston R.R., Elwin R.L., Barger I.A., No adaptation of Haemonchus contortus to genetically resistant sheep, Int. J. Parasitol. 22 (1992) 377-380.

[61] Woolaston R.R., Eady S.J., Australian research on genetic resistance to nematode parasites, in: Gray G.D., Woolaston R.R., Eaton B.T. (Eds.), Breeding for resistance to infectious diseases in small ruminants, Camberra ACIAR, 1995, pp. 53-75. 
[62] Yazwinski T.A., Goode L., Moncol D.J., Morgan G.W., Linnerud A.C., Haemonchus contortus resistance in straight breed and crossbred Barbados Black belly sheep, J. Anim. Sci. 51 (1980) 279-284.

[63] Yazwinski T.A., Goode L., Moncol D.J., Morgan G.W., Linnerud A.C., Parasite resistance in straightbred and crossbred Barbados Black belly sheep, J. Anim. Sci. 49 (1979) 919-926. 